\title{
Influence of Rootstocks on Growth Yield and Fruit Composition of Thompson Seedless Grapes Grown in the Pune Region of India
}

\author{
J. Satisha*, R.G. Somkuwar, J. Sharma, A.K. Upadhyay and P.G. Adsule \\ National Research Centre for Grapes, P.B. No. 3., Manjri Farm, Solapur Road, Pune - 412 307, Maharashtra, India \\ Submitted for publication: February 2009 \\ Accepted for publication: January 2010 \\ Key words: Thompson Seedless, rootstocks, growth, yield parameters, fruit composition, tropical climate
}

\begin{abstract}
The use of rootstocks is gaining importance in Indian viticulture due to problems associated with abiotic stresses, such as drought and salinity, and also to improve scion characteristics. Thompson Seedless is the only commercial cultivar grown for both fresh consumption and raisin making. Dog Ridge was the only popular rootstock used by grape growers prior to late 1990s. But this rootstock was known to induce more vigour in scions, resulting in reduced bud fruitfulness and thereby fruit yield. To identify alternate rootstocks suitable for Thompson Seedless, a study was initiated in the National Research Centre for Grapes, Pune, India during the year 2001. Five rootstocks with own rooted vines were evaluated in this study. During the initial years, Thompson Seedless grafted on Dog Ridge produced the highest yield, with good quality fruit. Over the years we could observe uneven bud sprouting, gaps on the cordon due to dead wood formation, and reduced yield in vines grafted on Dog Ridge rootstocks. In contrast, Thompson Seedless grafted on 110R performed well in terms of moderate vigour, increased fruitfulness and consistently higher yield. Dog Ridge and St. George produced a lower yield, owing to increased vigour measured in terms of pruning weight, total shoot length and cane diameter. Rootstocks 110R, 1103P and 99R are also known to increase water-use efficiency during critical growth stages of fruit bud differentiation and full bloom. No significant influence of rootstocks was observed for most of the fruit composition parameters. Larger and bolder berries were produced on Dog ridge and 110R rootstock, while they were the smallest on own rooted vines.
\end{abstract}

\section{INTRODUCTION}

Hot climate viticulture has gained significance in different tropical climatic regions of the world. The quality of table grapes produced under tropical and subtropical conditions, such as in Brazil, Venezuela, India and Thailand, has begun receiving international recognition. Table grapes occupy more than $90 \%$ of the area under grape cultivation in India. Of the table grape varieties, Thompson Seedless is a popular cultivar for both fresh consumption (local and export market) and raisin making. Traditional grape cultivation in India entailed growing commercial varieties of grapes on own roots. A decline in the productivity of table grapes in the major grapegrowing states of Maharashtra, Karnataka and Andhra Pradesh led the way to the utilisation of rootstocks in grape cultivation. Most of the table grape-growing districts in these states experience severe drought conditions during the critical growth stages, such as fruit bud differentiation, shoot maturity and full bloom. The use of drought-tolerant rootstocks would minimise the immediate effects of dry conditions and enable the variety to recover quickly. The potential problem of an increase in salinity in some of these states is of major concern and soil salinity has severely reduced the growth of own rooted vines. Due to these twin problems of drought and soil salinity, table grape growers are becoming increasingly aware about the benefits of rootstocks in overcoming some of these abiotic stresses, and are constantly seeking information on the performance characteristics and suitability of grapevine rootstocks for particular soil and climatic conditions.

In the tropical and subtropical climate of India, the absence of a dormancy period allows successive cycles and harvest programming throughout the year. It is necessary to break the bud dormancy in order to foster bud burst, and special management techniques have to be employed to overcome problems of low bud fertility and to control vigour. Under such conditions, Thompson Seedless puts forth more vegetative vigour, thus impeding fruit bud differentiation. Furthermore, the cultivation of this variety has become a high-risk activity due to the aggressiveness of traditional diseases such as downy mildew, powdery mildew and anthracnose. Vegetative vigour in terms of shoot length, internodal distance, shoot thickness and pruning weights are common characteristics of the growth and production of grapes. In a study, Williams and Smith (1991) observed more vegetative growth of Cabernet Sauvignon, expressed in high values of biomass and content of $\mathrm{N}$ and $\mathrm{P}$, in vines grafted on Arawan Rupestris Gargin rootstock, with the lowest vegetative growth on St. George.

The major functions of the grapevine root system are vine water relations, the uptake and translocation of nutrients, the synthesis and metabolism of plant growth substances and the storage of carbohydrates (Richards, 1983). Grape rootstocks have a primary effect on vine size measured in terms of pruning weights, as indicated by Pongraz (1983), Carbonneau and Casteran (1987), Howell (1987) and Pouget (1987). An increase in vine size when the canopy length is fixed results in crowding of shoots and internal canopy shading (Shaulis, 1982). Most secondary effects of rootstocks are mediated through their influence on vine size and internal canopy shading. For sustainable viticulture, it is important to know the interactions among rootstocks, different soil characters and scion productivity (Keller et al., 2001). The 
same rootstock may have different effects on the macronutrient content of scion varieties. A rootstock found to be beneficial for one cultivar may not be universally advantageous for others, as the interaction of stock and scion influences the vine performance more than the stock or scion alone (Hartmann et al., 1993).

With increased awareness about the use of rootstocks in overcoming the adverse effects of drought and salinity, growers started using Dog Ridge rootstock for the cultivation of Thompson Seedless grapes. However, in the tropical and subtropical climate of India, Dog Ridge induced more vegetative vigour in the scions, which reduced the bud fruitfulness of Thompson Seedless in the long run. This was evident from the experience of the few growers who were the first to employ Dog Ridge rootstocks in the Sangli region of Maharashtra State, India. In this context, there was an increased demand for an alternative rootstock that would be suitable for Thompson Seedless in the tropical and subtropical climate of the Indian subcontinent. Hence, this study was initiated with the objective to evaluate the performance of Thompson Seedless grafted onto five different rootstocks, with own rooted Thompson Seedless as a control.

\section{MATERIALS AND METHODS}

The trial was established in an experimental vineyard of the National Research Centre for Grapes at Pune, India. The soil type was deep black clay loam (vertisol), with a pH of about 8.2 and electrical conductivity (EC) of $1.6 \mathrm{~m} \mathrm{mhos} / \mathrm{cm}$. The trial included own rooted Thompson Seedless (Vitis vinifera) and five rootstocks that are commonly used in most tropical and subtropical climate viticulture. The rootstocks employed were as follows:

- Dog Ridge (Vitis champinii): Very high vigour with moderate drought tolerance

- $110 \mathrm{R}($ V berlandieri $\times$ Vitis rupestris $)$ : Moderate vigour with high drought tolerance

- 1103 P $($ V berlandieri $\times$ Vitis rupestris $)$ : High vigour with high drought tolerance

- $99 \mathrm{R}($ V berlandieri $\times$ Vitis rupestris $)$ : Moderate vigour with moderate drought tolerance

- St. George (Vitis rupestris): High vigour with moderate drought tolerance

Own rooted Thompson Seedless vines and ungrafted rootstock vines were planted during the month of February 2001 in a fully randomised block design, in four rows at a spacing of $3.0 \mathrm{~m} \times$ $1.8 \mathrm{~m}$ (row $\times$ vine), thus accommodating 726 vines per acre. Each row had 60 vines consisting of 10 own rooted vines and 10 each of other five rootstocks. The rootstocks, but not the own rooted vines, were wedge grafted in situ with Thompson Seedless scion, $45 \mathrm{~cm}$ above ground level, during September 2001 (Chadha \& Shikhamany, 1999). All the vines were trained to Geneva Double Curtain and drip irrigated as per the irrigation schedule developed for the region, based on pan evaporimeter readings. The experimental vines were fertilised with organic manure and commercial inorganic fertilisers through fertigation. Vines were pruned twice in a year - once during summer (popularly known as back pruning), to develop canes with differentiated fruit buds, and another pruning on the matured canes about five to six months after back pruning (popularly known as forward pruning), to encourage bunch development. The vines were cane pruned leaving six to eight nodes, depending on cane thickness. The first harvesting took place in March 2003. Experimental data was collected from the year 2004 onwards. Six vines of each stock:scion combination were selected in each replication, and there were four replications for each treatment.

Pruning weight was recorded as a measure of vine vigour after harvest during all the years of the study. The number of shoots was counted prior to forward pruning and the cane diameter was measured between the fifth and sixth node at shoot maturity. The girth of the stock and scion was measured above and below the graft joint every year using digital calipers. Days taken for sprouting were measured after forward pruning. The first sprouted bud with a fully expanded leaf was taken as an indicator to measure the days taken for sprouting.

The number of bunches was counted in each treatment before harvest, and harvesting was done manually. Average bunch weight and total yield per vine were calculated as per the standard procedures.

Fruit samples were collected from the designated treatments by replication prior to harvest. Fresh samples were utilised for the analysis of fruit quality parameters, such as total soluble solids, titratable acidity, berry diameter, berry weight, etc. Total soluble solids were measured using a hand-held temperature-compensated digital refractometer (ERMA, Japan), while titratable acidity was measured by titrating a known volume of juice with $0.1 \mathrm{NaOH}$ using phenolphthalein as indicator. The sugar acid ratio was derived using Brix and acidity values.

\section{Statistical analysis}

The Fisher method of ANOVA was performed using the SPSS statistical package version 11.0, and $p$ values of 0.05 and 0.01 were taken to be significant.

\section{RESULTS AND DISCUSSION}

The results of the experiment are presented and discussed in the following subsections.

\section{Vegetative growth}

Significant differences in pruning weight were recorded during all the years of the study. Pruning weight was significantly the highest on Dog Ridge (2.72 kg/vine) and St. George $(2.53 \mathrm{~kg} /$ vine), while the lowest pruning weight was produced by own rooted vines $(2.14 \mathrm{~kg} / \mathrm{vine})$. Pruning weight was intermediate in Thompson Seedless grafted on rootstocks $110 \mathrm{R}, 1103 \mathrm{P}$ and 99 R. Bud sprouting after forward pruning was quicker on own rooted Thompson Seedless vines (11 days), followed by those grafted on $110 \mathrm{R}$ rootstock. Delayed bud sprouting was recorded on Dog Ridge (20 days) during all the years of the study. There was a significant difference among the rootstocks in days taken for sprouting. Thompson Seedless grafted onto rootstocks $110 \mathrm{R}$, $1103 \mathrm{P}$ and $99 \mathrm{R}$ sprouted in about 15 to 17 days after pruning (Table 1).

Although a significant difference was observed for the number of canes during the first three years of the study, the numbers did not differ significantly in the fourth year when including the average of all four years. Overall, the highest number of canes was recorded on Dog Ridge during most years of the study, while it was least on own rooted vines and on the 1103 P rootstock. 
Significant differences were observed for cane diameter, total shoot length and stock:scion ratio during all the years of the study. The highest cane diameter was recorded on Dog Ridge $(8.2 \mathrm{~mm})$ during all four years, while it was least either on own rooted vines $(7.2 \mathrm{~mm})$ or on the 1103 P rootstock $(7.3 \mathrm{~mm})$. Total shoot length was highest on Dog Ridge and St. George and least on own rooted vines and $1103 \mathrm{P}$ rootstock. The stock to scion ratio at the graft joint was least on Dog Ridge rootstock during all the years, indicating greater girth of scion than that of stock on this rootstock. When the mean value of four years was taken into consideration, the lowest stock:scion ratio of 0.78 was recorded in Thompson Seedless grafted onto Dog Ridge, and the ratio was more towards 1.00 in Thompson Seedless grafted onto $110 \mathrm{R}$ (0.92). The stock:scion ratios of Thompson Seedless grafted onto other rootstocks are 0.86 on 1103 P, 0.86 on $99 \mathrm{R}$ and 0.82 on St. George.

Greater numbers of shoots, maximum shoot length and pruning weights were recorded in vines grafted on Dog Ridge rootstock, which agrees with the findings of Sommer et al. (1993) that the rootstocks Ramsey and Dog Ridge (Vitis champinii) conveyed high shoot length and vine vigour to the scions, with a tendency to develop dense canopies. They consequently observed the lesser penetration of sunlight into the leaf canopy and even negligible penetration of sunlight to the location of auxiliary buds in the vines grafted onto vigorous rootstocks relative to own rooted vines and those grafted onto less vigorous rootstocks. This explains the reduced fruit bud differentiation in more vigorous and denser canopies in comparison to vines with reduced shoot length and less vigour, which allow more sunlight to reach the fruiting buds during the period of fruit bud differentiation, resulting in higher fruitfulness.

Significant differences were observed in the number of days taken for sprouting, which is in accordance with the reports of several workers in the past, who established the influence of rootstocks on bud burst. Vines grafted on Dog Ridge sprouted about 20 days after pruning, while much earlier sprouting was recorded on own rooted vines. Prakash and Reddy (1990) reported the effect of different rootstocks on bud break in the grape cultivar Anab-e-Shahi, with a significant effect of rootstock on bud burst. For example, the number of days required for bud break was shorter with Gulabi (Isabella) as rootstock and was longer in vines grafted on Dog Ridge. These results are similar to the current findings of delayed bud sprouting on Dog Ridge rootstock. In contrast, Tangolar and Ergenoglu (1989) found that time to bud break was not significantly affected by rootstocks, although it tended to be earlier on $420 \mathrm{~A}$ and Rupestris du Lot.

In viticulture, growth abnormalities of the graft union have been linked to rootstock-scion incompatibility (Bioletti et al., 1921). However, despite some rootstocks showing swelling of the scions relative to the rootstocks at the graft union, they could not find any evidence of incompatibility of Sun Muscat scions on any of the rootstocks. They also suggested that the ratio of scion trunk diameter to rootstock trunk diameter was a good indicator of potential problems for productivity in grafted vines, and the ideal ratio was observed to be between 1.0 and 1.25 , with production problems likely to occur with ratios below 1.0 or higher than 1.33 . In the present study, although we could not see any incompatibility problems with the stock:scion ratio, which was observed to vary between 0.92 and 0.78 on the different stock:scion combinations, it was clear that there were differences in the growth behaviour of rootstocks in inducing more vigour in the scions. This was evident from the highest shoot length, cane diameter and more pruning weight on Dog Ridge rootstock, which had the lowest stock:scion ratio of 0.78

Hoover et al. (2004) observed marked differences among rootstock:scion combinations regarding the relationship of vine vigour and yield, with St. Pepin grafted onto MN Riparia 64 having low vigour but a higher yield in contrast to 3309C, which had high vigour and high yields, and MN 1065, which had low vigour and low yields. Similarly, Lider et al. (1965) established a relationship between pruning weight and fruitfulness, with increased fruiting efficiency from the individual spur on own rooted vines. This had lower pruning weight and decreased fruitfulness on Dog Ridge with a higher pruning weight.

\section{Yield parameters}

Yield, when averaged for four years of data, varied significantly among the rootstocks, with $110 \mathrm{R}$ producing highest yield, Dog Ridge, $1103 \mathrm{P}$ and $99 \mathrm{R}$ producing intermediate yield, and St. George and own rooted vines producing the lowest yield. However, when looking at the yield trend over the four years of this study, Dog Ridge was shown to produce more yield during the initial years of study - on par with $110 \mathrm{R}$ rootstock, but there was a gradual reduction in yield on Dog Ridge during the third and fourth year of study compared to that on $110 \mathrm{R}$. The lowest yield was recorded either on own rooted vines or on those grafted onto St. George rootstock. Although there was an increase in the yield per vine from 2005 until 2008, the year 2007 saw a severe incidence of powdery mildew in the entire experimental block, resulting in the loss of more than $40 \%$ of the yield (Table 2).

A greater number of bunches were recorded on $110 \mathrm{R}$ rootstock during all the years of the study, with the fewest bunches being either on St. George or Dog Ridge rootstock. Though the number of bunches differed significantly among rootstocks in the individual years of the study, the mean number of bunches did not differ significantly among the rootstocks. However, average bunch weight differed significantly among the rootstocks. The greatest bunch weight was recorded on Dog Ridge rootstock, followed by $110 \mathrm{R}$, while the smallest bunch weight was recorded on St. George and own rooted vines. The bunch weight was intermediate on rootstocks $1103 \mathrm{P}$ and $99 \mathrm{R}$.

Significant year-to-year variation in yield and yield components was recorded among the rootstocks, except in 2007. There was a severe incidence of powdery mildew during the fruit development stage in 2007, resulting in severe yield reduction on 1103 P, 99 R, St. George and own rooted vines.

The influence of rootstock on yield and physiological parameters has been reported by many workers (Williams \& Smith, 1991; Bica et al., 2000; Ollat et al., 2003). The results of these studies suggest that rootstocks differ in root distribution pattern and total root number, which influences the yield and pruning weight and also yield to pruning weight ratio (Morano \& Kliewer, 1994). Total yield and yield components of Thompson Seedless grafted onto different rootstocks varied significantly among rootstocks during the individual years of the study, and also when the average yield over the years was taken into consideration. This 
TABLE 1

Influence of rootstocks on vegetative parameters of Thompson Seedless.

\begin{tabular}{|c|c|c|c|c|c|c|c|c|c|c|c|c|c|c|c|}
\hline \multirow{2}{*}{ Rootstock } & \multicolumn{5}{|c|}{ Pruning weight (kg/vine) } & \multicolumn{5}{|c|}{ Days taken to sprout } & \multicolumn{5}{|c|}{ Number of canes } \\
\hline & 2004 & 2005 & 2006 & 2007 & Mean & 2004 & 2005 & 2006 & 2007 & Mean & 2004 & 2005 & 2006 & 2007 & Mean \\
\hline Dog Ridge & 2.13 & 2.82 & 2.82 & 3.14 & 2.72 & 16 & 20 & 21 & 24 & 20 & 69 & 61 & 56 & 51 & 68 \\
\hline $110 \mathrm{R}$ & 2.04 & 2.37 & 2.43 & 2.71 & 2.35 & 18 & 14 & 15 & 14 & 15 & 68 & 56 & 61 & 55 & 67 \\
\hline $1103 P$ & 2.24 & 2.15 & 2.33 & 2.22 & 2.21 & 18 & 17 & 14 & 16 & 16 & 53 & 51 & 53 & 50 & 53 \\
\hline $99 \mathrm{R}$ & 2.05 & 2.04 & 2.31 & 2.47 & 2.17 & 20 & 14 & 18 & 18 & 17 & 61 & 53 & 51 & 58 & 60 \\
\hline St. George & 2.13 & 2.60 & 2.43 & 3.02 & 2.53 & 18 & 19 & 16 & 14 & 17 & 63 & 46 & 46 & 50 & 64 \\
\hline Own rooted & 1.87 & 2.15 & 2.16 & 2.44 & 2.14 & 12 & 10 & 12 & 9 & 11 & 59 & 48 & 48 & 55 & 60 \\
\hline $\mathrm{S} \mathbf{E m} \pm$ & 0.049 & 0.07 & 0.092 & 0.066 & 0.089 & 0.305 & 0.383 & 0.776 & 0.390 & 1.092 & 2.130 & 2.464 & 2.464 & 2.518 & 4.104 \\
\hline \multirow[t]{3}{*}{ Level of sig. } & $*$ & $* *$ & $* *$ & $* *$ & $* *$ & $* *$ & $* *$ & $* *$ & $* *$ & $* *$ & $* *$ & $*$ & $*$ & NS & NS \\
\hline & \multicolumn{5}{|c|}{ Cane diameter (mm) } & \multicolumn{5}{|c|}{ Total shoot length $(\mathrm{cm})$} & \multicolumn{5}{|c|}{ Stock:scion ratio } \\
\hline & 2004 & 2005 & 2006 & 2007 & Mean & 2004 & 2005 & 2006 & 2007 & Mean & 2004 & 2005 & 2006 & 2007 & Mean \\
\hline Dog Ridge & 7.0 & 7.0 & 9.9 & 7.9 & 8.2 & 169.0 & 113.9 & 105.9 & 146.2 & 130.9 & 0.78 & 0.82 & 0.74 & 0.72 & 0.76 \\
\hline $110 \mathrm{R}$ & 7.1 & 7.1 & 9.3 & 7.5 & 7.9 & 86.9 & 94.7 & 94.1 & 95.8 & 91.0 & 0.97 & 0.78 & 0.88 & 0.77 & 0.91 \\
\hline $1103 P$ & 6.4 & 6.4 & 8.7 & 7.3 & 7.1 & 83.9 & 90.9 & 86.2 & 84.9 & 84.2 & 0.96 & 0.81 & 0.75 & 0.75 & 0.86 \\
\hline $99 \mathrm{R}$ & 6.7 & 6.7 & 8.6 & 7.4 & 7.7 & 77.9 & 95.4 & 107.6 & 100.4 & 94.0 & 0.91 & 0.69 & 0.84 & 0.81 & 0.86 \\
\hline St. George & 6.5 & 6.5 & 9.5 & 7.3 & 7.6 & 128.5 & 107.9 & 147.5 & 135.8 & 131.2 & 0.84 & 0.79 & 0.83 & 0.84 & 0.82 \\
\hline Own rooted & 6.5 & 6.5 & 8.3 & 7.2 & 7.1 & 58.8 & 84.8 & 97.0 & 99.4 & 83.0 & 1.00 & 1.00 & 1.00 & 1.00 & 1.00 \\
\hline $\mathbf{S} \mathbf{E m} \pm$ & 0.056 & 0.141 & 0.145 & 0.139 & 0.196 & 5.735 & 2.859 & 2.180 & 5.204 & 8.436 & 0.014 & 0.037 & 0.016 & 0.016 & 0.094 \\
\hline Level of sig. & $* *$ & $*$ & $* *$ & $*$ & $*$ & $* *$ & $* *$ & $* *$ & $* *$ & $* *$ & $* *$ & $* *$ & $* *$ & $* *$ & NS \\
\hline
\end{tabular}

is in accordance with several other studies conducted in various grape-growing regions of the world in the past. Vaile (1937) found that rootstocks could exert a definite influence on the behaviour of scion cultivars, as shown by increased vine vigour and yield. Snyder and Harmoon (1948) found that vigorous rootstocks produced the most wood in the first season of growth. Cultivars on weaker rootstocks produced less wood but performed fairly well in fruit production. Thus they suggested that yields were possibly negatively correlated with vine vigour, an aspect also demonstrated by Wolf and Pool (1988) and Parejo et al. (1995). In a study comprising 14 grape rootstocks and 12 scion varieties, Loomis (1952) found that some of the rootstocks improved yield, vigour and longevity in all the scion varieties compared to vines grown on their own roots.

Hedberg et al. (1986) recorded higher yields on all grafted cultivars than on own rooted vines, especially on Ramsey and Dog Ridge rootstocks. Ferree et al. (1996) reported increased yield from grafted Cabernet Franc and White Riesling than from own rooted vines. The effect of a particular variety is scion specific, which is evident from the studies of Foott et al. (1989), who observed improved yield of Cabernet Sauvignon and Chardonnay on $\mathrm{A} \times \mathrm{R} 1$, while $1202 \mathrm{C}$ induced more vigour in same cultivars. Similarly, in a study using soilless culture, Fardossi et al. (1995) found slower shoot growth of Gruner Veltline on 5C and Fercal, but more rapid growth was recorded on $1103 \mathrm{P}, 725 \mathrm{P}$ and $125 \mathrm{AA}$. Ripening was earlier on 1103 P, G1 and Riparia Sirbu than on other rootstocks. Ezzahouani and Larry (1997) recorded more vigour from the Italia cultivar on 101-11 and Rupestris du Lot, while the highest yield was recorded on $110 \mathrm{R}$ and $1103 \mathrm{P}$. Lovicu et al. (1999) also observed significant differences among rootstocks, with the yield of Chardonnay and Tocai being highest on 420 A, followed by these cultivars on Rupestris du Lot. There have also been reports of negative or indifferent effects of rootstocks on scion vigour and yield. Chardonnay vines on rootstocks $5 \mathrm{C}$, Kober 5 BB, G13, Teleki 8B, SO4, 1103P and 41B showed no significant effect on yields when compared to yields from own rooted vines (Boselli et al., 1992). The size of Chardonnay vines was reduced by rootstocks Kober 5 BB and 1103 P (Ferroni \& Scalabrelli, 1995). There were no significant differences between own rooted and grafted 'Gewurztraminer' regarding yield, fruit composition and pruning weight (Reynolds \& Wardle, 2001). Novello et al. (1996) showed that 'Erbaluce' grapes had higher vigour when grown on own roots rather than on rootstocks 10114, 420 A, Rupestris du Lot, Kober 5 BB or SO4. Sommer et al. (2001) found that grafted sultana vines were always more fruitful than own rooted vines. In the experiment involving nine grape 
TABLE 2

Influence of rootstocks on yield and yield components of Thompson Seedless grapes.

\begin{tabular}{|c|c|c|c|c|c|c|c|c|c|c|c|c|c|c|c|}
\hline \multirow{2}{*}{ Rootstock } & \multicolumn{5}{|c|}{ Yield per vine (kg) } & \multicolumn{5}{|c|}{ Yield per acre (t) } & \multicolumn{5}{|c|}{ Number of bunches per vine } \\
\hline & 2004 & 2005 & 2006 & 2007 & Mean & 2004 & 2005 & 2006 & 2007 & Mean & 2004 & 2005 & 2006 & 2007 & Mean \\
\hline Dog Ridge & 4.5 & 6.3 & 6.4 & 8.7 & 7.2 & 3.2 & 4.6 & 7.5 & 6.2 & 6.0 & 36 & 37 & 38 & 38 & 35 \\
\hline $110 \mathrm{R}$ & 4.6 & 6.4 & 6.3 & 13.5 & 9.0 & 3.4 & 4.6 & 7.6 & 9.8 & 7.4 & 38 & 38 & 37 & 59 & 45 \\
\hline $1103 P$ & 3.0 & 4.2 & 4.5 & 10.1 & 6.3 & 2.6 & 3.0 & 5.2 & 7.2 & 5.1 & 29 & 29 & 24 & 45 & 34 \\
\hline $99 \mathrm{R}$ & 3.2 & 4.5 & 4.2 & 11.1 & 7.1 & 2.7 & 3.2 & 5.8 & 7.9 & 5.8 & 24 & 24 & 29 & 60 & 38 \\
\hline St. George & 4.1 & 4.1 & 4.1 & 6.9 & 5.2 & 2.7 & 3.0 & 4.4 & 5.2 & 4.0 & 23 & 23 & 23 & 36 & 28 \\
\hline Own rooted & 3.8 & 3.8 & 3.8 & 11.7 & 6.4 & 2.6 & 2.7 & 5.06 & 8.3 & 4.9 & 22 & 22 & 22 & 60 & 40 \\
\hline $\mathbf{S} \mathbf{E m} \pm$ & 0.157 & 0.407 & 0.407 & 0.567 & 0.671 & 0.079 & 0.205 & 0.295 & 0.412 & 0.444 & 2.001 & 1.967 & 1.964 & 2.370 & 3.212 \\
\hline \multirow[t]{3}{*}{ Level of sig. } & $* *$ & $* *$ & $* *$ & $* *$ & $*$ & $* *$ & $* *$ & $* *$ & $* *$ & $* *$ & $* *$ & $* *$ & $* *$ & $* *$ & NS \\
\hline & \multicolumn{5}{|c|}{ Average bunch wt (g) } & & & & & & & & & & \\
\hline & 2004 & 2005 & 2006 & 2007 & Mean & & & & & & & & & & \\
\hline Dog Ridge & 208.0 & 207.2 & 210.9 & 226.5 & 246.5 & & & & & & & & & & \\
\hline $110 \mathrm{R}$ & 211.2 & 210.9 & 207.2 & 228.1 & 224.7 & & & & & & & & & & \\
\hline $1103 P$ & 174.2 & 174.8 & 183.7 & 221.1 & 191.5 & & & & & & & & & & \\
\hline $99 \mathrm{R}$ & 183.7 & 183.7 & 174.8 & 190.3 & 191.7 & & & & & & & & & & \\
\hline St. George & 175.0 & 175.7 & 175.7 & 167.6 & 174.2 & & & & & & & & & & \\
\hline Own rooted & 174.7 & 170.1 & 170.1 & 194.6 & 174.5 & & & & & & & & & & \\
\hline $\mathbf{S} \mathbf{E m} \pm$ & 4.703 & 14.32 & 14.32 & 11.17 & 10.60 & & & & & & & & & & \\
\hline Level of sig. & $* *$ & NS & NS & * & ** & & & & & & & & & & \\
\hline
\end{tabular}

cultivars and four rootstocks, Reynolds and Wardle (2001) did not observe significant differences among rootstocks in yield per vine, cluster weight and berry weight. They suggested that rootstocks might not provide any significant advantage over own rooted vines under conditions in the arid parts of the Pacific Northwest of America and in British Columbia.

Apart from vegetative parameters that influence yield, several other physiological processes may also be influenced by rootstocks and indirectly affect the yield and quality of Thompson Seedless. This is supported by several other studies on the effect of rootstocks on physio-biochemical processes in scion leaves. The rootstock affects photosynthesis and dry matter partitioning by the scion cultivars, which influences vegetative growth and yield. During (1994) studied the influence of rootstock on scion photosynthesis and concluded that the effect of rootstock on gas exchange parameters is scion specific. The rate of photosynthesis and stomatal conductance were also influenced by rootstock genotype and age. In some cases, grafting increased the rate of photosynthesis more than could be attributed to changes in stomatal conductance. Bica et al. (2000) found that the effect of rootstock was significantly higher on leaf area, chlorophyll content, stomatal conductance and quantum yield. Chardonnay vines grafted onto SO4 showed lower photosynthesis, quantum yield, stomatal conductance and chlorophyll content than those grafted onto 1103 P. Pinot Noir vines grafted onto SO4 and 1103 P showed similar assimilation rates. Kober 5BB improved leaf area, stomatal conductance and transpiration rate in comparison to SO4. In the present study, various physiological parameters were measured during the critical growth stages of fruit bud differentiation and full bloom. A higher photosynthetic rate and lower transpiration rate was observed in Thompson Seedless grafted onto 110R, 1103P and $99 \mathrm{R}$ rootstocks, and the least was recorded on St. George and own rooted vines (data not shown). The increased yield in these rootstocks may be attributed to increased carboxylation efficiency and increased water-use efficiency, which supports the earlier findings of Satisha et al. (2008) indicating 110R and $1103 \mathrm{P}$ to be drought tolerant rootstocks with high stomatal conductance and water-use efficiency under dry climatic conditions.

In addition to the effect of rootstocks on photosynthesis, transpiration and water-use efficiency, rootstocks are also known to influence the partitioning of dry matter. Williams and Smith (1991) observed no significant difference in dry mater partitioning by Cabernet Sauvignon grafted onto $\mathrm{A} \times \mathrm{R} 1$, St. George and Teleki 5C. However, Tardaguila et al. (1995) reported that dry weight portioning by Cabernet Sauvignon differed on different rootstocks, in that 101-14 Mgt favoured dry weight accumulation 
TABLE 3

Influence of rootstocks on fruit quality parameters of Thompson Seedless grapes.

\begin{tabular}{|c|c|c|c|c|c|c|c|c|c|c|c|c|c|c|c|}
\hline \multirow{2}{*}{ Rootstock } & \multicolumn{5}{|c|}{50 berry weight (g) } & \multicolumn{5}{|c|}{ Berry diameter (mm) } & \multicolumn{5}{|c|}{ TSS $\left({ }^{\circ} \mathbf{B}\right)$} \\
\hline & 2004 & 2005 & 2006 & 2007 & Mean & 2004 & 2005 & 2006 & 2007 & Mean & 2004 & 2005 & 2006 & 2007 & Mean \\
\hline Dog Ridge & 75.5 & 76.6 & 70.7 & 156.6 & 123.0 & 13.4 & 13.4 & 13.1 & 16.8 & 15.7 & 22.2 & 22.2 & 22.2 & 21.1 & 21.5 \\
\hline $110 R$ & 70.7 & 70.7 & 76.6 & 152.0 & 111.5 & 13.1 & 13.1 & 13.4 & 15.8 & 15.4 & 22.1 & 22.2 & 22.2 & 20.5 & 21.6 \\
\hline $1103 P$ & 66.0 & 65.1 & 64.3 & 152.7 & 106.2 & 12.5 & 12.4 & 12.4 & 16.4 & 14.8 & 21.8 & 21.6 & 21.7 & 19.6 & 21.1 \\
\hline $99 \mathrm{R}$ & 64.0 & 64.3 & 65.1 & 143.2 & 105.0 & 12.5 & 12.4 & 12.4 & 15.6 & 14.5 & 21.8 & 21.7 & 21.6 & 20.0 & 21.3 \\
\hline St. George & 66.7 & 67.8 & 67.8 & 132.0 & 97.7 & 12.3 & 12.2 & 12.2 & 15.1 & 14.1 & 21.7 & 21.9 & 21.9 & 21.6 & 21.3 \\
\hline Own rooted & 63.0 & 62.5 & 62.5 & 136.5 & 99.7 & 12.1 & 12.2 & 12.2 & 15.3 & 14.2 & 21.5 & 21.3 & 21.3 & 19.0 & 21.0 \\
\hline $\mathbf{S} \mathbf{E m} \pm$ & 2.709 & 3.792 & 3.792 & 5.404 & 3.263 & 0.101 & 0.383 & 0.383 & 0.309 & 0.110 & 0.110 & 0.271 & 0.271 & 0.654 & 0.393 \\
\hline \multirow[t]{3}{*}{ Level of sig. } & NS & NS & NS & NS & $* *$ & $* *$ & NS & NS & $*$ & $* *$ & $* *$ & NS & NS & NS & NS \\
\hline & \multicolumn{5}{|c|}{ Acidity (mg/L) } & \multicolumn{5}{|c|}{ Sugar:acid ratio } & & & & & \\
\hline & 2004 & 2005 & 2006 & 2007 & Mean & 2004 & 2005 & 2006 & 2007 & Mean & & & & & \\
\hline Dog Ridge & 0.77 & 0.62 & 0.57 & 0.97 & 0.81 & 28.6 & 26.6 & 31.1 & 21.2 & 26.8 & & & & & \\
\hline $110 \mathrm{R}$ & 0.72 & 0.57 & 0.62 & 0.94 & 0.79 & 31.2 & 30.1 & 31.2 & 21.6 & 27.5 & & & & & \\
\hline $1103 P$ & 0.67 & 0.56 & 0.49 & 0.90 & 0.74 & 31.5 & 31.4 & 31.2 & 21.6 & 28.8 & & & & & \\
\hline $99 \mathrm{R}$ & 0.72 & 0.49 & 0.56 & 0.97 & 0.78 & 30.1 & 27.1 & 29.1 & 20.8 & 27.7 & & & & & \\
\hline St. George & 0.81 & 0.58 & 0.58 & 0.87 & 0.79 & 26.9 & 24.8 & 32.1 & 24.1 & 27.2 & & & & & \\
\hline Own rooted & 0.69 & 0.62 & 0.62 & 0.87 & 0.71 & 30.2 & 31.1 & 34.4 & 21.3 & 30.1 & & & & & \\
\hline $\mathbf{S} \mathbf{E m} \pm$ & 0.007 & 0.029 & 0.029 & 0.041 & 0.021 & 0.902 & 0.889 & 0.725 & 0.733 & 1.088 & & & & & \\
\hline $\mathrm{P}<0.05$ & $* *$ & NS & NS & NS & NS & $*$ & $* *$ & $*$ & NS & NS & & & & & \\
\hline
\end{tabular}

in canes, while $41 \mathrm{~B}$ favoured accumulation in clusters. The same concept may hold good in the present study, whereby the highvigour rootstocks such as Dog Ridge and St. George must have influenced the scions to accumulate dry matter in the vegetative portions like the shoot, trunk and canes, while rootstocks such as 110R, 1103P and 99R must have encouraged accumulation in the clusters.

\section{Fruit composition}

Most of the fruit quality components displayed very little response to the rootstock treatment in most of the years of this study, with the exception of berry diameter. Bigger and bolder berries, as indicated by higher berry diameter and berry weight, were recorded on Dog Ridge rootstocks during all the years of study. Although it differed significantly when the mean of all the years was taken into consideration, berry diameter did not differ significantly in 2006 and 2007 (Table 3).

It was interesting to note that, during the initial years of the study, there was a significant difference between all the fruit composition parameters, including soluble solids, titratable acidity, berry diameter and sugar:acid ratio, for the different rootstocks. But over the years there was no significant difference between any of the parameters, including the mean values of all the years.
The influence of rootstock on fruit composition has been reported by several workers, especially in relation to wine grapes, with a close link between fruit quality and wine made from those grapes. Fruit composition parameters that eventually affect wine quality include soluble solids, organic acids, $\mathrm{pH}$, phenolic and anthocyanins, monoterpenes and other components (Jackson \& Lombard, 1993). Hale and Brien (1978) were the first to investigate the influence of Salt Creek rootstock on the composition and quality of Shiraz grapes and wine. Their results showed that grafted Shiraz had larger berries with lower soluble solids and higher $\mathrm{pH}$, titratable acidity, malate and potassium. Cirami et al. (1984) recorded higher juice $\mathrm{pH}$ in Shiraz grafted onto Ramsey, Dog Ridge, Harmony, Schwarzmann and $1613 \mathrm{C}$ than in own rooted vines. Wine made from this juice had greater colour density and more ionised anthocyanins and the lowest wine colour hue. Similarly, grafted Shiraz recorded higher wine potassium, $\mathrm{pH}$ and colour hue than own rooted vines (Walker et al., 2000). Kubota et al. (1993) grafted Fujimori grapes onto seven different rootstocks and found that the glucose and fructose content of the pulp was higher in berries grafted onto $3309 \mathrm{C}$, $3306 \mathrm{C}$ and $8 \mathrm{~B}$, although the predominant sugars in the berry pulp and skin were glucose and fructose, irrespective of the rootstocks. The highest level of skin anthocyanin was observed in berries from vines grafted onto $3306 \mathrm{C}$. 
From long-term studies in the lightly textured soils of the Mildura region, Victoria, Australia, Thompson Seedless grafted onto Dog Ridge and Salt Creek (both of Vitis champinii) recorded the highest yields, but those grafted onto $110 \mathrm{R}$ and $420 \mathrm{~A}$ produced a lower yield than from own rooted vines (Sauer, 1972). This suggests that the performance of rootstocks is specific to the soil, climate and location, which is clear from the present study, in that rootstock 110R produced the highest yield, while Dog Ridge and St. George produced the lowest yield in the heavy, black cotton soils of the semiarid tropics in India. In addition to the effect of rootstock on photosynthesis, transpiration and water-use efficiency, the partitioning of dry matter might also be affected by the rootstock.

\section{CONCLUSION}

It is evident from this study that the growth, yield and fruit composition parameters of Thompson Seedless vary with the rootstock used. In the semiarid tropical climate of India, the rootstock Dog Ridge increased the vigour of Thompson Seedless, which resulted in reduced fruitfulness and decreased yield. This is also evident from the increased girth of the scion above the graft union in contrast to the stock girth below the graft union. Rootstocks $110 \mathrm{R}$ and $99 \mathrm{R}$ were found to be promising with respect to the induction of moderate vegetative vigour in the scion, with consistently higher yield during the period of this study. Although Dog Ridge recorded reduced yield, it produced bolder berries in terms of berry diameter and berry weight, which are among the important characteristics of table grapes for export purposes. Rootstocks 110R, $1103 \mathrm{P}$ and $99 \mathrm{R}$ have good potential in the tropical and subtropical climate of India due to their droughttolerant characteristics, such as increased water-use efficiency and high proline content, which was established in our earlier studies (Satisha et al., 2008). Most of the fruit composition parameters of Thompson Seedless were not influenced by the rootstocks. Countries such as Brazil, India, Thailand and Venezuela play a leading role in the production of tropical grapes. However, tropical viticulture is expanding, since there are vineyards being planted in different countries in America (Bolivia, Colombia, Peru, Guatemala), Africa (Madagascar, Namibia, Tanzania) and Asia (Vietnam, China). The findings of this study may help in comparing the results obtained from rootstock evaluation studies conducted in tropical situations. Although the findings of this rootstock evaluation study on Thompson Seedless grapes in the semiarid tropics of India are quite promising, the study was too short to draw long-term conclusions for the industry. The study needs to be continued to observe the long-term performance of rootstocks under such conditions.

\section{LITERATURE CITED}

Bica, D., Gay, G., Morando, A., Soave, E. \&. Bravdo, B.A., 2000. Effects of rootstock and Vitis vinifera genotype on photosynthetic parameters. Acta Hort. 526, 373-379.

Bioletti, F.T., Flossfeder, F.C.H. \& Way, A.E., 1921. Phylloxera resistant rootstocks. Bulletin No. 331, Agricultural Experimental Station, Berkeley, California.

Boselli, M., Fregoni, M., Vercesi, A. \& Volpe, B., 1992. Variation in mineral composition and effects on the growth and yield of Chardonnay grapes on various rootstocks. Agricoltura Ricerca 14, 138-139.

Carbonneau, A. \& Casteran, P., 1987. Optimization of vine performance by the lyre training system. In: Lee, T. (ed). Proc. 6th Aust. Wine Ind. Tech. Conf., Australian Industrial Publishers, Adelaide, Australia. pp. 194 - 204.
Chadha, K.L. \& Shikhamany, S.D., 1999. The grapes - improvement, production and post harvest management practices. Malhothra Publications, New Delhi.

Cirami, R.M., McCarthy, M.G. \& Glenn, T., 1984. Comparison of the effects of rootstock on crop, juice and wine composition in a replanted nematode-infected Barossa Valley vineyard. Aust. J. Expt. Ag. Anim. Husbandry 24, 283-289.

During, H., 1994. Photosynthesis of ungrafted and grafted grapevines: effects of rootstock genotype and plant age. Am. J. Enol. Vitic. 45, 297-299.

Ezzahouani, A. \& Larry, L.E., 1997. Effect of rootstock on grapevine water status productivity and grape quality of cultivar 'Italia'. Bulletin de l'OIV 70, 703-713.

Fardossi, A., Brandes, W. \& Mayer, C., 1995. Influence of different rootstock cultivars on growth, leaf nutrient content and must quality of cultivar Gruner Veltliner. Mitteilungen Klosterneuburg, Rebe und Wein, Obstbau und Fruchteverwertung 45, 3-15.

Ferree, D.C., Cahoon, G.A., Ellis, M.A., Scurlock, D.M. \& Johns, G.R., 1996. Influence of eight rootstocks on the performance of 'White Riesling' and 'Cabernet Franc' over five years. Fruit Varieties J. 50, 124-130.

Ferroni, G. \& Scalabrelli, G., 1995. Effect of rootstock on vegetative activity and yield in grapevine. Acta Hort. 388, 37-42.

Foott, J.H., Ough, C.S. \& Wolpert, J.A., 1989. Rootstock effects on wine grapes. Calif. Ag. 43, 27-29.

Hale, C.R. \& Brien, C.J., 1978. Influence of Salt Creek rootstock on composition and quality of Shiraz grapes and wine. Vitis 17, 139-146.

Hartmann, H.T., Kester, D.E. \& Davies, F.T., 1993. Plant propagation - principles and practices. Prentice Hall, New Delhi, India.

Hedberg, P.R., McLeod, R., Cullins, B. \& Freeman, B.M., 1986. Effect of rootstocks on production, grape and wine quality of Shiraz vines in Murrambidge irrigation area. Aust. J. Expt. Agri. 26, 511-516.

Hoover, R.E., Hemstad, P., Larson, D., Mackeazie, J, Zambreno, K. \& Propson, F., 2004. Rootstock influences on scion vigor, hardiness, yield and fruit composition of St. Pepin grapes. In XXVI International Horticulture Congress; Viticulture Living with limitations, Toronto, Canada.

Howell, G.S., 1987. Vitis rootstocks. In: Rom, R.C. \& Carlson, R.F. (eds). Rootstocks for fruit crops. Wiley and Sons, New York. pp. $451-474$.

Jackson D.I. \& Lombard, P.B., 1993. Environmental and management practices affecting grape composition and wine quality - a review. Am. J. Enol. Vitic. 44, 409-430.

Keller, M., Kummer, M. \& Vasconcelos, M.C., 2001. Soil nitrogen utilization for growth and gas exchange by grapevines in response to nitrogen supply and rootstock. Aust. J. Grape and Wine Res. 7, 2-11.

Kubota, N., Li, X.G. \& Yasui, K., 1993. Effects of rootstocks on sugar, organic acid, amino acid, and anthocyanin contents in berries of potted 'Fujiminori' grapes. J. Japan. Soc. Hort. Sci. 62, 363-370.

Lider, L.A., Ferrari, N.L. \& Kissler, J.J., 1965. Effect of several nematode resistant rootstocks on vine vigor, crop level and nutrition with the grape variety, Grenache. Am. J. Enol. Vitic. 16, 42-48.

Loomis, N.H., 1952. Effect of fourteen rootstocks on yield, vigor, and longevity of twelve varieties of grapes at Meridian, Mississippi. Proc. Amer. Soc. Hort. Sci. 59, 125-132.

Lovicu, G., Pala, M., \& Farci, M., 1999. Effect of rootstock on the vegetative productive performance of Cannonau. Informatore Agrario 55, 87-90.

Morano, L. \& Kliewer, W.M., 1994. Root distribution of three grapevine rootstocks grafted to Cabernet Sauvignon grown on a very gravelly clay loam soil in Oakville, California. Am. J. Enol. Vitic. 45, 345-348.

Novello, V., Bica, D. \& De Palma, L., 1996. Rootstock effects on vegetative productive indices in grapevine cv. Erbaluce trained to pergola system. Acta Hort. $427,233-240$

Ollat N., Tandonnet J.P., Bordenave L., Decroocq S., Geny L., Gaudillere J.P., Fouquet R., Barrieu F. \& Hamdi, S., 2003. La vigueur conferee par le portegreffe: hypothèses et pistes de recherches. Bull de l'OIV 76(869 870), 581-595. [In French].

Parejo, J., Minguez, S., Sella, J. \& Espinas, E., 1995. Sixteen years of monitoring the cultivar Xarello (Vitis vinifera L.) on several rootstocks. Acta Hort. 388, 123-128.

Pongraz, D.P., 1983. Rootstocks for grapevines. David Phillip Publisher, Cape Town. 
Pouget, P., 1987. Usefulness of rootstocks for controlling vine vigor and improving wine quality. Acta Hort. 206, 109-118.

Prakash, G.S. \& Reddy, N.N., 1990. Effect of different rootstocks on budbreak in grape cv. Anab-e-Shahi. Crop Research 3, 51-55.

Reynolds, A.G. \& Wardle, D.A., 2001. Rootstocks impact vine performance and fruit composition of grapes in British Columbia. Hort. Technol. 11, 419-427.

Richards, D., 1983. The grape root system. Hort. Rev. 5, 127-168.

Satisha, J., Ramteke, S.D. \& Karibasappa, G.S., 2008. Physiological and biochemical characterization of grape rootstocks. S. Afr. J. Enol. Vitic. 28, 163-168.

Sauer, M.R., 1972. Rootstock trials for sultana grapes on light textured soils. Aust. J. Expt. Agri. and An. Husbandry 12, 107-111.

Shaulis, N.J., 1982. Responses of grapevines and grapes to spacing of and within canopies. In: Webb, D. (ed). Grape and Wine Centennial Symposium Proceedings, University of California: Davis. pp. $353-360$.

Snyder, E. \& Harmoon, F.N., 1948. Comparative value of nine rootstocks for ten vinifera grape varieties. Proc. Amer. Soc. Hort. Sci. 51, 287-294.

Sommer, K.J., Clingeleffer, P.R. \& Ollat, N. 1993. Effects of minimal pruning on grapevine canopy development, physiology and cropping level in both cool and warm climates. Vitic. Enol. Sci. 48, 135-139.
Sommer, K.J., Islam, M.T., \& Clingeleffer, P.R., 2001. Sultana fruitfulness and yield as influenced by season, rootstock and trellis type. Aust. J. Grape and Wine Res. 7, 19-26.

Tangolar, S. \& Ergenoglu. F., 1989. The effects of different rootstocks on the levels of mineral elements in the leaves and the carbohydrate contents of the canes of some early maturing grape cultivars. Doga, Turk Tarim ve Ormancilik Dergisi $13(3 b), 1267-1283$

Tardaguila, J., Bertamini, M., Giulivo, C. \& Scienza, A., 1995. Rootstock effects on growth, dry weight partitioning and mineral nutrient concentration of grapevine. Acta Hort. 388, 111-116.

Vaile, J.E., 1937. The influence of rootstocks on the yield and vigor of American grapes. Proc. Amer. Soc. Hort. Sci. 35, 471-474.

Walker, R.R., Read, P.E. \& Blackmore, D.H., 2000. Rootstock and salinity effects on rates of berry maturation, ion accumulation and color development in Shiraz grapes. Aust. J. Grape and Wine Res. 6, 227-239.

Williams, L.E. \& Smith, R.J., 1991. The effect of rootstock on the partitioning of dry weight, nitrogen and potassium, and root distribution of Cabernet Sauvignon grapevines. Am. J. Enol. Vitic. 42, 118-122.

Wolf, T.K. \& Pool, R.M., 1988. Effects of rootstock and nitrogen fertilization on the growth and yield of Chardonnay grapevines in New York. Am. J. Enol. Vitic. $39,29-33$. 